Chapter 15

\title{
Leishmaniasis: Possible New Strategies for Treatment
}

\author{
Alane Beatriz Vermelho, Claudiu T. Supuran, \\ Verônica Cardoso, Dayanne Menezes, \\ Jefferson Rocha de Andrade Silva, \\ Jose Luiz Pinto Ferreira, \\ Ana Claudia Fernandes Amaral and \\ Igor A. Rodrigues
}

Additional information is available at the end of the chapter

http://dx.doi.org/10.5772/57388

\section{Introduction}

\subsection{Leishmaniasis}

Leishmaniasis is a vector-born disease caused by protozoan parasites in the genus Leishmania. Leishmaniasis is a potentially lethal, neglected disease that mostly affects economically disadvantaged individuals in many developing countries. Human infection occurs through the bite of infected female phlebotomine sand flies followed by injection of promastigote forms into the skin, which penetrate the macrophages and/or other types of mononuclear phagocytic cells. The promastigotes then transform into amastigotes (tissue stage of the parasite) in these cells and replicate, resulting in the bursting of the host cell and infection of other mononuclear phagocytic cells. Sand flies become infected by ingesting amastigote-infected cells during blood meals. These evolutionary forms transform into promastigotes in the gut of the insect and migrate to the proboscis, infecting other people through the bite (Scheme 1).

Depending on the Leishmania species involved and the host immune response, infection can lead to tegumentary or visceral manifestations of the disease. The tegumentary form of leishmaniasis (TL) includes cutaneous (CL), mucocutaneous (MCL), and diffuse (DL) clinical manifestations. All tegumentary forms have a major impact on patient life, because the skin lesions can lead to disfigurement and social stigmatization [2, 3]. Visceral leishmaniasis (VL), or Kala-azar, affects organs and internal tissues such as spleen, liver, bone marrow, and lymph 


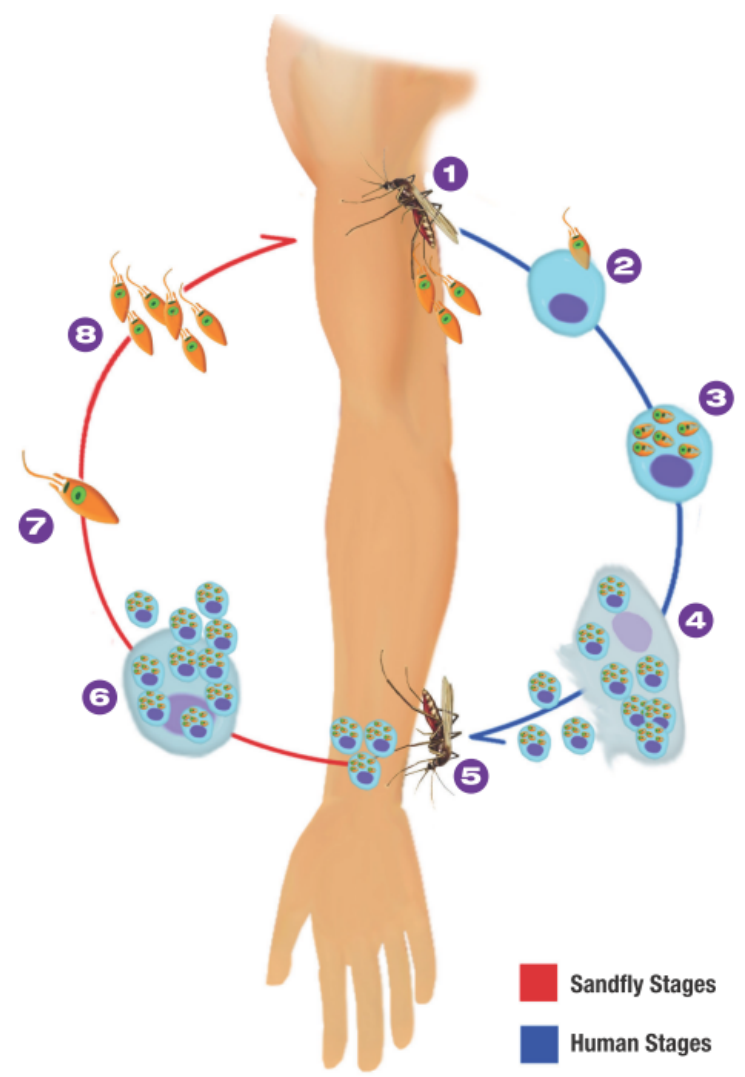

Scheme 1. Leishmaniasis life cycle. 1- sand flies inject promastigotes during blood meals;2-promastigote infects macrophages and other types of mononuclear phagocytic cells;3-promastigotes transform into amastigotes; 4-amastigotes multiply. 5- sand flies become infected by ingesting macrophages infected with amastigotes during blood meals; 6 - parasitized cells ; 7- in sand flies, amastigotes transform into promastigotes, in the gut; 8- promastigotes divide and migrate to proboscis based on CDC, 2013 [1].

nodes. With the progression of VL, splenomegaly and hepatomegaly lead to a distended abdomen and pain. Eventually, VL may lead to death caused by secondary infections, severe anemia, or organ failure [4]. Both TL and VL are endemic diseases in several countries. In fact, the number of cases of leishmaniasis may be underestimated because only 40 of the 88 countries where the disease frequently occurs report cases on a regular basis $[5,6]$.

The World Health Organization (WHO) estimates that 1.6 million new leishmaniasis cases occur annually, of which 500,000 correspond to VL (90\% of them occurring in Bangladesh, Brazil, Ethiopia, India, Nepal, and Sudan) and 1.1 million to CL (90\% of them occurring in Afghanistan, Algeria, Brazil, Iran, Peru, Saudi Arabia, Sudan, and Syria) [7]. Leishmaniasis currently affects an estimated 12 million people and approximately 350 million people live at risk of infection [1], whereas an estimated half a million people die annually of VL. In addition, 
immunosuppressive conditions such as AIDS contribute to the emergence of severe clinical forms of the disease. To date, the greatest prevalence of Leishmania-HIV co-infection has been reported in the Mediterranean basin [8, 9]. In some east African regions, up to $40 \%$ of patients with VL are co-infected with HIV, which further complicates treatment [10].

\section{Current drugs}

Currently, most antileishmanial drugs can be considered orphan drugs. In fact, leishmaniasis, Chagas disease, are examples of tropical neglected diseases (TND) as they receive little attention from governments and the pharmaceutical industry. For instance, by the 2000s, global investment in new anti-parasitic drugs was only about $0.1 \%$ of global investment in research [11, 12]. Additionally, the lack of human vaccines for leishmaniasis makes chemotherapy the primary method used to control the disease. Despite the existence of several chemotherapics to treat human leishmaniasis, many of them are new formulations of ancient drugs [13]. The chemotherapeutic agents currently used in the treatment of VL and TL such as stibogluconate of sodium (Pentostam ${ }^{\circledR}$ ), N-methylglucantime $\left(\right.$ Glucantime $^{\circledR}$ ), pentamidine (Pentacarinato ${ }^{\circledR}$ ), and amphotericin B (Fungizone ${ }^{\circledR}$ ) do not possess activity when orally administered and require parenteral administration for long periods [14]. In addition, those chemotherapeutic agents are very expensive and cause severe side effects due to their high toxicity [15].

Taken together, all these factors contribute to poor patient adherence or abandonment of treatment. In turn, treatment failure has a great impact on the spread of the disease and the emergence of drug-resistant strains. However, the introduction of new chemotherapeutic agents, including liposomal amphotericin B (AmBisome $\left.{ }^{\circledR}\right)$, paramomycin, and miltefosin has certainly improved the current scenario for the treatment of leishmaniasis. AmBisome $^{\circledast}$ has become the first-choice drug for treating VL in several countries. For instance, this treatment is currently used in Bihar, India, because pentavalent antimonials have become less effective against parasites [16, 17]. However, none of these drugs are free of severe side effects and the development of new strategies and/or alternative therapeutic agents remain crucial.

The incorporation of amphotericin B into lipid formulations has brought new perspectives to the treatment of leishmaniasis, resulting in the incorporation of several other drugs to different lipid formulations, including meglumine antimoniate [18], furazolidone [19], paromomycin sulfate [20] and miltefosin [21]. Conventional chemotherapeutics usually have difficulty reaching target tissues in therapeutic concentrations and are also associated with toxic effects on healthy organs and tissues. Thus, drug delivery approaches should improve the efficacy, specificity, tolerability, and therapeutic index of antiparasitic agents [12]. However, despite advances in the efficacy of existing drugs, the toxic potential of these substances must be considered. Thus, the search for new strategies and/or alternative therapeutic agents is crucial. 


\section{Natural products and drug delivery systems against leishmaniasis: state- of-the-art}

The use of tools and materials at the nanoscale enabled the creation of nanoparticulate formulations such as liposomes, microemulsions, and microcapsules of great interest to the pharmaceutical industry. Drug delivery systems using liposomes are the ones most studied because of their high biocompatibility, ease of preparation, and chemical versatility [22]. Basically, liposomes are microscopic vesicles composed of one or more concentric lipid bilayers separated by aqueous media. Liposomes can encapsulate hydrophilic and lipophilic substances; the former stay in the aqueous compartment, whereas the latter are inserted into the membrane. Because liposomes are biodegradable, biocompatible, and non-immunogenic, they are highly versatile for research, therapeutic, and analytical applications [23]. These vesicles are primarily consisted of phospholipids (either synthetic or natural), sterols, and antioxidants [24]. Lipids with a cylindrical shape such as phosphatidylcholine, phosphatidylserine, phosphatidylglycerol, and sphingomyelin, which tend to form a stable bilayer in aqueous solution, are commonly used in liposomal formulations. Phosphatidylcholine is the most employed lipid in liposomal formulation studies due to its great stability against $\mathrm{pH}$ or salt concentration variations in the medium [25]. The pharmacokinetic properties of liposomes can be simply modified by changing the chemical composition of the bilayer components. Moreover, peptides, polysaccharides, or affinity ligands such as antibodies can be incorporated into liposomes [12].

Phospholipid-based liposomes are usually used to change the pharmacokinetics profile of several drugs, either natural or synthetic ones. Natural products such as crude extracts, fractions, or isolated phytocompounds have been incorporated into different colloidal carriers, including liposomes, with promising results. As expected in the incorporation of synthetic drugs, lipid formulations enhance the solubility and bioavailability of extracts and bioactive compounds derived from plants. Additional benefits of phytoformulations include: (i) protection from toxicity; (ii) enhanced pharmacological activity; (iii) enhanced stability; (iv) increased retention time; and (v) protection from physical and chemical degradation [26,22]. The ability of colloidal carriers to improve tissue macrophages distribution may have an impact on Leishmania infection. The tendency of nanoformulations, especially liposomes, to be captured by the mononuclear phagocyte system may be an additional advantage in the treatment of leishmaniasis. In fact, intraperitoneal and intravenous administration of liposomes proved to be a good biodistribution system for drugs in the treatment of VL, because it increased drug accumulation in macrophage-rich tissues such as liver and spleen, thus reducing the toxicity level to other tissues and organs [27].

Since ancient times, products from plant, mineral, and animal sources have been used in traditional medicine to fight many human diseases. In fact, for centuries traditional medicine has been the only health care system available for the prevention and treatment of several diseases in different cultures. Currently, the practice of traditional medicine still has a great impact on the health of people who have no access to modern health care practices. In fact, an estimated $80 \%$ of people living in developing countries rely almost completely on traditional medicinal practices to meet their primary medication needs [28-30]. Thus, the use of natural products as medicines has attracted the interest of research laboratories around the world 
seeking new bioactive molecules. Among the most studied natural products, plants are a valuable source of compounds with antileishmanial activity. Active compounds derived from plant extracts have been described by several laboratories worldwide [31-34]. The antileishmanial activity of several crude extracts and fractions derived from plants has been attributed to compounds belonging to diverse chemical groups, including phenolic compounds (e.g., chalcones, flavonols, aurones, lignans, coumarins, quinines, tannins), terpenoids (monoterpenes, sesquiterpenes, diterpenoids, triterpenes), and alkaloids (indole alkaloids, isoquinoline alkaloids, quinoline alkaloids) [35-37]. In fact, phytoscience may be an important tool in the search for novel antileishmanial agents with fewer side effects and lower potential costs. Secondary metabolites isolated from plant extracts or essential oils can be used in several different ways for the development of drugs. Nanoformulation-based delivery systems are a promising approach to developing novel antileishmanial agents.

\begin{tabular}{|c|c|c|c|c|}
\hline Species & Family & $\begin{array}{c}\text { Geographical origin } \\
\text { (country) }\end{array}$ & Part used & References \\
\hline $\begin{array}{l}\text { Aesculus } \\
\text { hippocastanum }\end{array}$ & Hipocastanaceae & not cited & Seeds & {$[40]$} \\
\hline $\begin{array}{l}\text { Andrographis } \\
\text { paniculata }\end{array}$ & Acanthaceae & (India) & Leaves & {$[41,42]$} \\
\hline Bacopa monniera & $\begin{array}{l}\text { Scrophulariaceae } \\
\text { (Plantaginaceae) }\end{array}$ & (India) & Leaves & {$[43,44]$} \\
\hline $\begin{array}{l}\text { Camptotheca } \\
\text { acuminata }\end{array}$ & Cornaceae & (China) & bark, stem & {$[45]$} \\
\hline Curcuma longa & Zingiberaceae & (India) & rhizome & {$[46]$} \\
\hline $\begin{array}{l}\text { Fagopyrum } \\
\text { esculentum }\end{array}$ & Polygonaceae & (India) & not cited & {$[39,47]$} \\
\hline Mimusops elangii & Sapotaceae & (India) & Seeds & {$[48]$} \\
\hline Peganum harmala & Nitrariaceae & (India) & Seeds & {$[49,50]$} \\
\hline Piper aduncum & Piperaceae & (Brazil) & inflorescence & [51] \\
\hline Piper nigrum & Piperaceae & (India) & Seeds & {$[52,53]$} \\
\hline Swertia chirata & Gentianaceae & $\begin{array}{l}\text { Himalayan region } \\
\text { (India) }\end{array}$ & aerial part & {$[54,55]$} \\
\hline Taxus baccata & Taxaceae & $\begin{array}{c}\text { Peloponnese region } \\
\text { (Greece) }\end{array}$ & $\begin{array}{l}\text { needles, } \\
\text { branches }\end{array}$ & {$[56]$} \\
\hline Terminalia bellerica & Combretaceae & - & stem bark & [57] \\
\hline $\begin{array}{l}\text { Zanthoxylum } \\
\text { chiloperone }\end{array}$ & Rutaceae & Cordillera (Paraguay) & stem bark & {$[58,59]$} \\
\hline
\end{tabular}

Table 1. Natural sources of active substances used in nanoformulations against Leishmania.

Table 1 lists the natural sources used in nanoformulations to improve the bioavailability of antileishmanial drugs, thus increasing their expected therapeutic efficacy. However, the botanical species used for isolation of the active constituent have not been described in some 
formulations such as those containing asiaticoside and acaciaside [38], whereas others have a plant origin but were purchased commercially [39]. It should be noted that the most studied species listed in Table 1 are native to developing countries, where the popular use of medicinal plants is widespread.

\section{Phytocompound nanoformulations and antileishmanial activity}

In the last decades, advances in nanoscience have enabled the development of nano-range materials approved for therapeutic use or in clinical development stage. In fact, many encapsulation matrices have been approved by the Food and Drug Administration (FDA) for use in humans, i.e., a wide range of naturally or chemically modified cyclodextrins that are extensively used in medicine and food fields [60,61]. Similarly, vesicular systems such as liposomes, niosomes, nanoparticles, and microspheres are very useful and have many advantages in delivering drugs of natural origin, representing a promising approach for the treatment of several diseases, including leishmaniasis. Nanoformulations prepared with compounds from medicinal plants and their antileishmanial activity are summarized in Table 2. Liposomes, niosomes, and nanoparticles are the main formulations investigated.

Saponins (liposomes) and alkaloids (nanoparticles) are among the main plant constituents used to prepare nanoformulations. Liposomes are mainly formed by a mixture of phosphatidyl choline (PC), cholesterol (Chol), and phosphatidic acid (PA), usually in a 7:4:1 molar ratio [55, 38], whereas nanoparticle formulations have polylactide (PLA) as their main ingredient, providing greater stability, biocompatibility, and an efficient delivery system compared to liposomal structures $[50,57]$. The antileishmanial properties of each nanoformulation are briefly cited below.

Flavonoids are among the most common phenolic compounds found in the human diet and a variety of members of this family has been described as bioactive agents. Significant antiprotozoal activity of flavonoids has been reported against Trypanosoma and Leishmania species. Quercetin (Fig. 1) is a widely studied food-derived flavonoid with several biological effects, including antioxidant, antihypertensive, anti-inflammatory, and antiprotozoal activities. Quercetin inhibits parasite arginase activity $[62,63]$ and induces the production of superoxide anion, hydrogen peroxide, and other reactive oxygen species (ROS) by infected cells. Thus, ROS generation induced by quercetin could be crucial for maximal antiparasitic activity, because ROS are naturally generated by macrophages as a mechanism to kill intracellular parasites such as Leishmania [64, 65]. In fact, liposomal, niosomal, microspherulated, and nanocapsulated quercetin formulations have been tested to evaluate the best drug delivery system. In hamster models of $L$. donovani infection, all quercetin vesicular formulations reduced the parasite load compared to the free form of the drug. Nanocapsulated quercetin is more effective than non-capsulated quercetin in the control of leishmaniasis $87 \%$ reduction in spleen parasite burden) and its pronounced activity may be related to vesicular composition and size. Moreover, drug efficacy may be inversely correlated to the size of vesicular forms [39]. 
Similarly, the incorporation of terpenoids into nanoparticle carriers has also shown promising results. The search for active molecules to treat leishmaniasis is very laborious, because most molecules have low solubility. The incorporation of andrographolide (Fig. 2), a diterpenoid extracted from the herbaceous species Andrographis paniculata (Acanthaceae), with different poly (d,l-lactide-co-glycolide) (PLGA) nanoformulations enhanced the antileishmanial activity of andrographolide against axenic and intracellular amastigote forms of L. donovani. Among the formulations tested, the $175 \mathrm{~nm}$ andrographolide-loaded nanoparticles exhibited the best antileishmanial activity $\left(\mathrm{IC}_{50}=36\right.$ and $28 \mu \mathrm{M}$ for axenic and intracellular amastigotes, respectively) [66]. Andrographis paniculata can be considered an interesting source of antileishmanial agents. While 14-deoxy-11-oxoandrographolide (Fig. 2), an andrographolide-derived diterpenoid, reduced spleen parasite load in hamster models of L. donovani infection in 39\%, liposomal, niosomal, and microspherulated formulations of this substance suppressed spleen parasite load by 78,91 , and $59 \%$, respectively. In addition, the toxicity of 14-deoxy-11oxoandrographolide to hepatic tissue also decreased after incorporation of 14-deoxy-11oxoandrographolide into colloidal carriers, as demonstrated by the normal levels of serum alkaline phosphatase (ALP) and serum glutamate pyruvate transaminase (SGPT) in the blood [67]. Interestingly, particle size also proved to be an important factor for drug delivery efficacy. In fact, nanoparticles in a size range below $200 \mathrm{~nm}$ have been associated with increased phagocytosis by Leishmania-infected macrophages [68].

\begin{tabular}{|c|c|c|c|c|c|}
\hline Formulations & Active ingredients & $\begin{array}{l}\text { Administration } \\
\text { Route }\end{array}$ & $\begin{array}{l}\text { Target and } \\
\text { Parasite reduction }\end{array}$ & $\begin{array}{l}\text { \% Entrapment } \\
\text { efficiency }\end{array}$ & References \\
\hline $\begin{array}{l}\text { Liposomes } \\
\text { Niosomes }\end{array}$ & Amarogentin & SC & $\begin{array}{l}\text { L. donovani } \\
\text { (LP 69\% and NS 90\%) }\end{array}$ & $\begin{array}{l}33 \\
24\end{array}$ & [55] \\
\hline $\begin{array}{l}\text { Mannose-coated } \\
\text { Liposomes } \\
\text { Liposomes }\end{array}$ & Piperine & SC & $\begin{array}{l}\text { L. donovani } \\
\text { (ML 90\%; LP 77\%) }\end{array}$ & 22 & [52] \\
\hline Nanoparticles & $\begin{array}{l}\text { 2',6'-dihydroxy-4'- } \\
\text { methoxychalcone }\end{array}$ & IP & $\begin{array}{l}\text { L. amazonensis } \\
(53 \%)\end{array}$ & 92 & [51] \\
\hline Liposomes & camptothecin & IP & $\begin{array}{l}\text { L. donovani } \\
(55 \%)\end{array}$ & 2.7 & [45] \\
\hline $\begin{array}{l}\text { Liposomes } \\
\text { Niosomes } \\
\text { Micropspheres } \\
\text { Nanoparticles }\end{array}$ & Quercetin & SC & $\begin{array}{l}\text { L. donovani } \\
\text { (LP 51\%; NS 68\%; MS 44\%; } \\
\text { NP } 87 \% \text { ) }\end{array}$ & $\begin{array}{l}40 \\
50 \\
09 \\
-\end{array}$ & [39] \\
\hline $\begin{array}{l}\text { Liposomes } \\
\text { Niosomes } \\
\text { Nanoparticles } \\
\text { Microspheres }\end{array}$ & bacopasaponin C & SC & $\begin{array}{l}\text { L. donovani } \\
\text { (LP 81\%; NS 86\%; NP 79\%; } \\
\text { MS 91\%) }\end{array}$ & $\begin{array}{l}30 \\
30 \\
30 \\
50\end{array}$ & [44] \\
\hline $\begin{array}{l}\text { Liposomes } \\
\text { Niosomes } \\
\text { Micropspheres }\end{array}$ & $\begin{array}{l}\text { 14-deoxi-11- } \\
\text { oxoandrographolide }\end{array}$ & SC & $\begin{array}{l}\text { L. donovani } \\
\text { (LP 78\%; NS 91\%; MS 59\%) }\end{array}$ & $\begin{array}{l}10 \\
1 \\
10\end{array}$ & [42] \\
\hline Liposomes & Harmine & SC & L. donovani & 65 & [50] \\
\hline
\end{tabular}




\begin{tabular}{|c|c|c|c|c|c|}
\hline Formulations & Active ingredients & $\begin{array}{l}\text { Administration } \\
\text { Route }\end{array}$ & $\begin{array}{l}\text { Target and } \\
\text { Parasite reduction }\end{array}$ & $\begin{array}{l}\% \text { Entrapment } \\
\text { efficiency }\end{array}$ & References \\
\hline Niosomes & & & \multirow{2}{*}{ (LP 60\%; NI 70\%; NP 80\%) } & 60 & \\
\hline Nanoparticles & & & & 20 & \\
\hline Lipid nanospheres & Piperine & IV & $\begin{array}{l}\text { L. donovani } \\
(52-90 \%)\end{array}$ & 100 & [53] \\
\hline Liposomes & asiaticoside & $\mathrm{nr}$ & $\begin{array}{l}\text { L. donovani } \\
\text { (LP 62\%) }\end{array}$ & $\mathrm{Nd}$ & \\
\hline Liposomes & acaciaside & $\mathrm{nr}$ & $\begin{array}{l}\text { L. donovani } \\
\text { (LP 92\%) }\end{array}$ & $\mathrm{Nd}$ & [30] \\
\hline $\begin{array}{l}\text { Microemulsion } \\
\text { Nanoparticles }\end{array}$ & bassic acid & SC & $\begin{array}{l}\text { L. donovani } \\
\text { (ME 62\%; NP 78\%) }\end{array}$ & $\begin{array}{l}100 \\
50\end{array}$ & {$[48]$} \\
\hline $\begin{array}{l}\text { Nanogels } \\
\text { Nanoparticles }\end{array}$ & arjunglucoside I & SC & $\begin{array}{l}\text { L. donovani } \\
\text { (NG 79\%; NP75\%) }\end{array}$ & $\begin{array}{l}80 \\
60\end{array}$ & {$[57]$} \\
\hline Nanoparticles & andrographolide & in vitro assay & $\begin{array}{l}\text { L. donovani } \\
\text { Axenic amastigotes } \\
\left(\mathrm{IC}_{50}=36 \pm 4 \mu \mathrm{M} / \mathrm{mL}\right) \\
\text { Amastigotes in macrophage } \\
\left(I C_{50}=28 \pm 2 \mu \mathrm{M} / \mathrm{mL}\right)\end{array}$ & 80 & {$[66]$} \\
\hline Nanoparticles & $\beta$-aescin & in vitro assay & $\begin{array}{l}\text { L. infantum } \\
\text { Amastigotes }\left(I C_{50}=1.04\right. \\
\pm 0.23 \mathrm{ug} / \mathrm{ml})\end{array}$ & $2.8-31.9$ & {$[40]$} \\
\hline Gold nanoparticles & quercetin & in vitro assay & $\begin{array}{l}\text { L. donovani } \\
\text { Axenic amastigotes } \\
\left(\mathrm{IC}_{50}=15 \pm 3 \mu \mathrm{M} / \mathrm{ml}\right) \\
\text { Amastigotes in macrophage } \\
\left(\mathrm{IC}_{50} 10 \pm 2 \mu \mathrm{M} / \mathrm{ml}\right)\end{array}$ & 77 & [69] \\
\hline
\end{tabular}

LP: liposomes; NS: niosomes; ML: manose-coated liposomes; NP: nanoparticles; MS: microspheres; ME: microemulsions; NG: nanogels.

SC: subcutaneous; IP: intraperitoneal; IV: intravenous.

nr: not reported; nd: not determined.

Table 2. Phytocompound nanoformulations and antileishmanial activity.

Triterpenoidic or steroidal saponins directly reduce cell viability via membrane disruption. The mode of action of saponins is related to its aglycone portion, which binds to membrane sterols, leading to the formation of transmembrane pores and loss of intracellular content. This feature of saponins demonstrates the toxic potential of these molecules, hampering their use as antileishmanial agents. Conversely, polymeric nanoparticles composed of PLGA were successfully used to improve the efficacy of $\beta$-aescin (Fig. 2), the main saponin isolated from the seeds of horse-chestnut Aesculus hippocastanumi (Sapindaceae), lowering its cytotoxic effect for mammalian cells [40]. Bacopasaponin-C (Fig. 2) was firstly reported as an antileishmanial 
<smiles>COc1cc(O)c(C(=O)/C=C/c2ccccc2)c(O)c1</smiles>

2', 6'-dihidroxy-4'-methoxychalcone<smiles>O=c1c(O)c(-c2ccc(O)c(O)c2)oc2cc(O)cc(O)c12</smiles>

Quercetin

Figure 1. Structure of phenolic compounds loaded in nanoformulations.

agent in 2002, but its mechanism of action remains unclear. This glycoside extracted from Bacopa monnieri (Plantaginaceae) has glucose and rhamnose residues attached to the triterpenoid aglycone moiety. The glucose residue may be responsible for targeting bacopasaponin$\mathrm{C}$ to glucose receptors on the cellular surface. Incorporation of bacopasaponin-C into various delivery carriers (niosomes, microspheres, nanoparticles, and liposomes) improved its antileishmanial activity. After six-day treatment with subcutaneous injections of liposomal, niosomal, microencapsulated, or nanocapsulated formulations of bacopasaponin-C, hamster models of L. donovani infection showed a significant reduction in spleen parasite burden (81, 86,79 , and $91 \%$, respectively) compared to free drug-treated animals (40\%). At the same dose $(1.7 \mathrm{mg} / \mathrm{kg})$, the smallest vesicles had the best efficacy, as follows: nanocapsules $>$ niosomes $>$ liposomes $>$ microspheres [44]. Another glycoside with remarkable activity against Leishmania parasites has been isolated from the indigenous plant Swertia chirata (Gentianaceae): amarogentin (Fig. 2) is a secoiridoid glycoside with the capacity to inhibit DNA-topoisomerase I, an essential enzyme related to Leishmania viability. Liposomal and niosomal formulations of amarogentin $(2.5 \mathrm{mg} / \mathrm{kg})$ reduced spleen parasite load by 69 and $90 \%$, respectively, whereas free drug at equivalent dose reduced parasite load by 39\%. In addition, both SPTG and ALP activity remained close to normal levels when liposomal or niosomal formulations of this iridoid were used in murine models [55].

The amide alkaloid piperine (Fig. 3) extracted from Piper nigrum (Piperaceae), an Indian species commonly used in traditional medicine, has been reported as a potent antileishmanial acting against both visceral (L. donovani) and tegumentary (L. amazonensis) leishmaniasis [70, 71]. In vivo tests have shown that piperine entrapped into liposomes and mannose-coated liposomes were effective against murine models of $L$. donovani infection. After 12-day treatment with liposomal and mannose-coated liposomal formulations of this alkaloid (four doses, $6 \mathrm{mg} / \mathrm{mL}$ ) administered subcutaneously, a reduction in parasite burden of approximately 77 and $90 \%$, respectively was achieved. Free piperine not only was less effective in reducing parasite burden (29\%)but also had higher toxicity to liver compared to the colloidal carriers (ALP = 20.5 $\mu \mathrm{mol}$ of $p$-nitrophenol released $/ \mathrm{min} / \mathrm{dL}$ of sera and SGPT $=77.2 \mu \mathrm{mol}$ of sodium pyruvate $/ \mathrm{min} /$ L of sera) [52]. Nevertheless, better results can be achieved by using lipid nanospheres of piperine (LN-P). A single dose $(5 \mathrm{mg} / \mathrm{kg}$ ) of the lipid formulation composed of stearylamine (LN-P-SA) reduced parasite burden in liver and spleen of L. donovani-infected hamsters by $90 \%$ and $85 \%$ after 15 days post infection, respectively. Despite the size of the vesicles (about 884.6 $\mathrm{nm}$ ), the efficacy of LN-P-SA may be related to the preferential uptake of stearylamine-bearing 
360

Leishmaniasis - Trends in Epidemiology, Diagnosis and Treatment
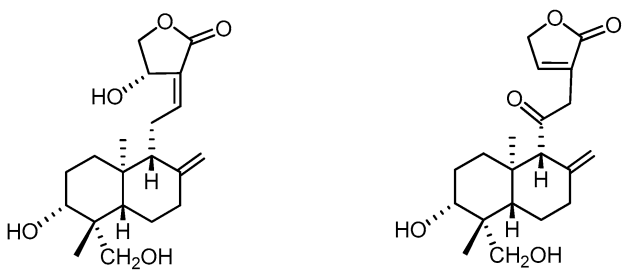

Andrographolide

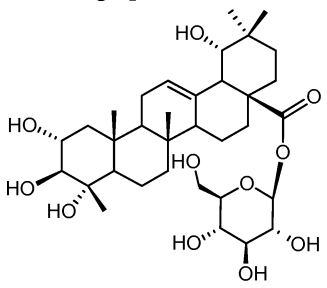

14-deoxy-11-oxoandrographolide

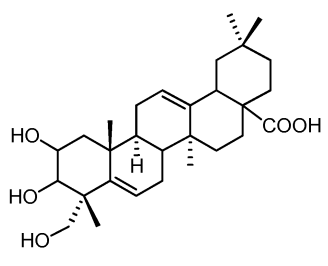<smiles>C=CC1C(OC2CC3(C=C)CCOC(=O)C3=CO2)OC(CO)[C@H](O)C1OC(=O)c1c(O)cc(O)cc1-c1cccc(O)c1</smiles>

Amarogentin
Arjunglucoside I

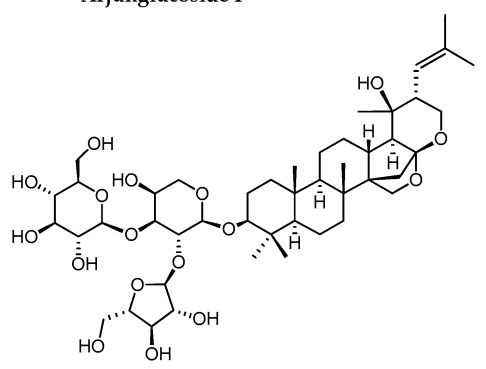

Bacopasaponin-C

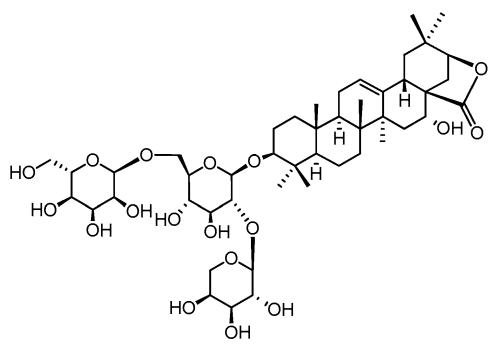

Bassic acid

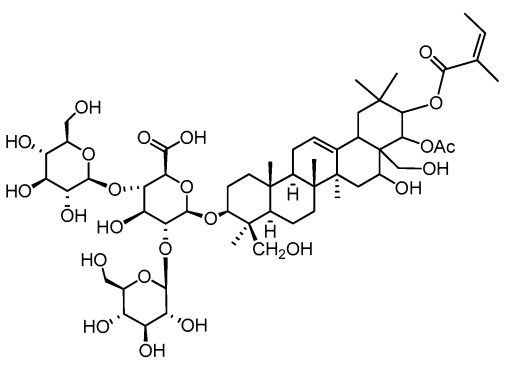

$\beta$-aescin

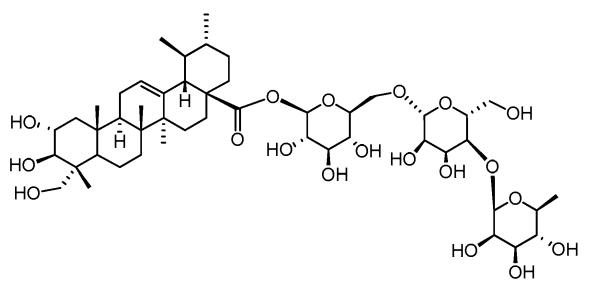

Acaciaside

Asiaticoside

Figure 2. Structure of terpenoids loaded in nanoformulations. 
positively charged liposomes $(+24.2 \mathrm{mV})$ by peritoneal macrophages compared to neutral and negatively charged vesicles [53].

$\beta$-carboline alkaloids such as harmane, harmaline, and harmine were initially described as potent psychoactive and hallucinogenic agents. However, a wide range of pharmacological activities have been reported for those compounds, including those against Leishmania parasites [72]. Harmine (Fig. 3), isolated from Peganum harmala (Nitrariaceae), displays in vitro anti-L. donovani promastigote activity at $25 \mu \mathrm{g} / \mathrm{mL}$. Recently, this alkaloid was incorporated into liposomes, niosomes, and nanoparticles at an equivalent dose of $1.5 \mathrm{mg} / \mathrm{kg}$ body weight, and after six doses administered subcutaneously to L. donovani-infected murine models, all harmine-entrapped vesicular formulations were able to reduce spleen parasite burden, especially nanosomes (a reduction of about 79\%). Nevertheless, the mechanism of action of harmine against Leishmania remains unclear and may be related to necrotic membrane damage.

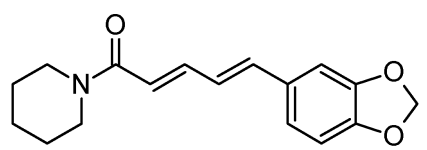

Piperine

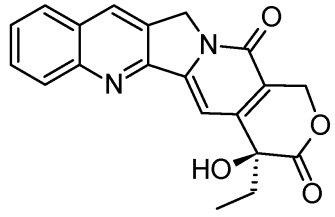

Camptothecin

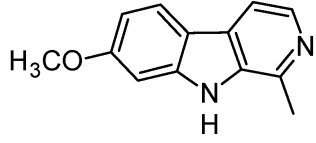

Harmine

Figure 3. Structure of alkaloids loaded in nanoformulations.

The search for new compounds with antileishmanial activity in medicinal plants is an interesting strategy, however most studies are still limited to basic research and probably only a few compounds will reach stages of clinical trials and development of new drugs. The combination of phytochemistry and nanoformulations may open up new perspectives in the search for new antileishmanial drugs, because drug delivery systems based on nanoformulations can improve the effectiveness of natural compounds making them more attractive to the development of new therapeutic targets. Due to their structural versatility in terms of size, composition, and ability to incorporate hydrophilic or lipophilic substances, there are many possible applications of nanoparticulate formulations in the treatment and control of leishmaniasis.

\section{Parasite targets for new drugs}

Parasite resistance, cost, side effects, toxicity, and other therapy issues prompt an urgent need to identify and develop new drugs and alternative targets for leishmaniasis treatment [73, 74, 10]. Metabolic pathways such as glycolytic pathway [75, 76], polyamine biosynthesis [77, 78], glyoxalase pathway [79, 80], uptake and turnover of phospholipids/sphingolipids [81, 82], microtubule biosynthesis [83, 84], and folate metabolism [85] have been targeted. 
The development of drugs directed at new targets such as parasite enzymes represents another approach in the search for new antileishmanial drugs. Arginase is a recently described target for the treatment of leishmaniasis. The enzyme is localized in the glycosome, a subcellular organelle found in some trpypanosomatids such as Leishmania. Inhibition of the arginase pathway causes inhibits the polyamine biosynthetic pathway, resulting in antileishmanial activity [86].

Other enzyme systems investigated as potential targets for antileishmanial drug action include nitric oxide synthase, DNA topoisomerase, trypanothione redutase, superoxide dismutase enzymes, and hypoxanthine-guanine phosphoribosyltransferase [74]; heme oxygenase-1 [87]; ribose 5-phosphate isomerase B [88]; dihydroorotate dehydrogenase [89]; ornitine decarboxylases [62]; Abl family kinases and phosphoinositide 3-kinase $\gamma$ [90-93]; and spermidine synthase $[94,95]$.

A total of 154 peptidases were detected in the Leishmania major genome, including serine, cysteine, aspartic, threonine, and metallopeptidases. The cysteine peptidase-specific inhibitor K11777 has shown that these peptidases are necessary for parasite growth [96]. Even though some inhibitors have been developed but failed to kill parasites, peptidases are promising targets [97-99].

Carbonic anhydrases (CAs, EC 4.2.1.1) are a new target that are starting to be studied for Leishmania. CAs are metalloenzymes that catalyze $\mathrm{CO}_{2}$ hydration to bicarbonate and protons, and five CA classes have been identified: $\alpha, \beta, \gamma, \delta$, and $\zeta$. The reaction catalyzed by CAs is essential in the regulation of acid-base balance in organisms [100,101]. A $\beta$-carbonic anhydrase was recently cloned and characterized from Leishmania donovani chagasi, and enzyme-specific inhibitors were tested against Leishmania [102].

The death of the parasite by inhibiting an enzyme or pathway essential for parasite survival and non-essential for the host requires the exploration of differences between these pathways or enzymes [103]. Thus, new Leishmania molecules should be studied and the possibility of developing rational and more effective drugs with less harmful side effects for the host investigated. Finally, new Leishmania chemotherapeutic targets and new approaches to the development of drugs should be considered [104, 93, 105].

\section{Synthetic drugs}

No vaccine candidates for leishmaniasis are currently under animal or clinical trials. Thus, new and effectives drugs should be investigated. In the last years, several drugs have been studied to find potential new drugs with desirable characteristics. Leishmaniasis is expanding in developed countries and in North America and Europe, which has alarmed health authorities worldwide [106]. Although leishmaniasis is treatable, it is difficult to control due to the absence of an effective vaccine, the adaptation of the vector and reservoir hosts to human environments, and the emergence of resistant lineages [107]. The first-line chemotherapy drugs available are pentavalent antimonials [108], whereas pentamidine and amphotericin B are second-line therapies, but these are associated with limited effectiveness, a long-term treatment, toxicity, 
and significant side effects [109]. Consequently, there is an urgent need to discover new drugs that are effective against leishmaniasis [110].

Some compounds have been studied and regarded as promising new drugs. The stilbene trans-3,4',5-trimethoxy-3'-amino-stilbene (TTAS) showed a $\mathrm{LD}_{50}$ of $2.6 \mathrm{lg} / \mathrm{mL}$ against Leishmania infantum with low toxicity. The action mechanism is the disruption of the mitochondrial membrane potential and the ability to block Leishmania parasites during the G2/M phase of cell cycle [111].

$N$-butyl-1-(4-dimethylamino)phenyl-1,2,3,4-tetrahydro- $\beta$-carboline-3-carboxamide has been tested against Leishmania amazonensis and ultrastructural alterations, depolarization of the mitochondrial membrane with loss of cell membrane integrity, and increased formation of mitochondrial superoxide anions were detected, indicating that this compound induced mitochondrial dysfunction [111].

Besides the lack of an effective vaccine against leishmaniasis, in some East African regions, up to $40 \%$ of patients with visceral leishmaniasis are co-infected with HIV, which complicates the treatment. Peptidase inhibitors, used to treat HIV-infected individuals are a new route that needs more studies. HIV-1 protease inhibitors such as Indinavir, Saquinavir, and others have been tested to treat leishmaniasis and inhibition of parasite growth has been reported at high drugs concentrations [9].

Other synthetic antileishmanial compounds are currently being developed an evaluated for therapeutic use. $\beta$-carbolines from various natural and synthetic sources have shown diverse biological activities. A total of 22 compounds were synthesized and tested in vitro against Leishmania donovani, out of which six compounds $(4,5,10,11,19$, and 22$)$ showed more activity than the standard miltefosine $\left(\mathrm{IC}_{50}=12.07 \pm 0.82 \mathrm{lM}\right)$, with compound 4 being the most potent $\left(\mathrm{IC}_{50}=2.16 \pm 0.26 \mathrm{lM}\right)$ [112]. Moreover, a semi-synthetic berberine analogue, 5,6-didehydro-8,8diethyl-13-oxodihydroberberine chloride showed nanomolar level potency against in vitro models of leishmaniasis, malaria, and trypanosomiasis, as well as activity in an in vivo visceral leishmaniasis model [113]. Tamoxifen is a synthetic estrogen that has been successfully used to prevent recurrence of breast cancer in women who are estrogen-receptor positive. Miguel et al. (2008) [114] reported the leishmanicidal activity of tamoxifen in vitro using BALB/c mice infected with L. amazonensis and treated with this compound for 15 days.

Diospyrin, a bis-naphthoquinone isolate from the tree Diospyros montana and its semisyntheitic derivatives showed inhibitory activity against Leishmania spp. The di-epoxide derivative of diospyrin (D17) was more effective against L. donovani promastigotes than diospyrin. The same derivative tested in L.donovani BHU1216 selectively inhibited intracellular amastigotes. Computational docking studies demonstrated that D17 could inhibit $L$ donovani ornithine decarboxylase but not trypanothione reductase [115].

Therapeutic approaches using drugs that act on structures of vital importance to the parasite but absent or sufficiently different in their hosts have been explored by several research groups. Indotecan and AM13-55, are TopIB poisons with indenoisoquinoline structure. Both compounds were tested against $L$ infantum and the results compared with paromomycin, a leishmanicidal drug. The tests were done on a murine BALB/c model of splenocytes infected with L. infantum. The results showed that Indotecam reduced more than $80 \%$ of the parasite 
burden of the spleen and liver, indicating that this compound is a potential drug against visceral leishmaniasis [116].

TiO2@Ag nanoparticles (TiAg-Nps) produce reactive oxygen species (ROS), which have an antimicrobial effect, including antileishmanial effects on Leishmania tropica and Leishmania infantum promastigotes and amastigotes, mainly non-visible light-exposed TiAg-Nps [117]. Twenty-four porphyrin precursors and derivatives were evaluated against Trypanosoma brucei, L. donovani, and Plasmodium sp. The perforine $4 \mathrm{i}$ derivative showed the best activity against T. brucei with a MEC value of $6.25 \mathrm{mM}$, but the compound was not active against intramacrophage amastigotes of L. donovani [118].

Another approach used in studies is the combination of drug therapies aimed at finding the most effective and secure one. Pam3Cys (an in-built immunoadjuvant and TLR2 ligand) and miltefosine were combined and the resulting combination was evaluated. All experiments were done in BALB/c mouse. Parasitic inhibition significantly increased in groups treated with combinations of the drugs compared to groups receiving miltefosine and Pam3Cys separately. Moreover, increased production of Th1 cytokines, RNS, ROS, and $\mathrm{H}_{2} \mathrm{O}_{2}$, as well as increased phagocytosis were observed during the study of immunological alterations [119].

Several aromatic/heterocyclic sulfonamides and 5-mercapto-1,3,4-thiadiazoles were recently investigated against $L$. donovani $C A s$. The sulfonamides were medium potency-weak inhibitors, but some heterocyclic thiols inhibited the enzyme with KIs in the range of $13.4-52 \mathrm{nM}$. Microscopic studies revealed cell swelling and structural alterations on the flagellar pocket such as presence of vacuoles. Autophagic vacuoles that cause intracellular damages and parasite death, and accumulation of intracytoplasmic electron-dense granules were also induced by the inhibitors. These result suggest that $\beta$-CA from Leishmania is a potential new antileishmanial drug target [102].

\section{Conclusions}

Leishmaniasis is a neglected, potentially lethal infectious disease caused by parasites in the genus Leishmania that affects many developing countries. Infection can lead to tegumentary or visceral manifestations of the disease. The tegumentary form of leishmaniasis (TL) includes cutaneous, mucocutaneous, and diffuse clinical manifestations, whereas visceral leishmaniasis (VL), or Kala-azar, affects organs and internal tissues. The treatment of VL is challenging and long. Treated patients need monitoring and hospitalization. Therapeutic problems include toxicity and teratogenicity of the available drugs, and low response in human immunodeficiency virus (HIV)/Leishmania co-infections. In addition, drug resistance is increasing. Moreover, leishmaniasis received little attention from governments and the pharmaceutical industry until the last decade. The absence of either prophylactic or preventive vaccine candidates makes it further difficult to control the disease.

The development of new parasite targets and synthetic drugs along with the research on natural products represents a major strategy for the discovery of new compounds against Leishmania sp. 


\section{Acknowledgements}

This study was supported by grants from Coordenação de Aperfeiçoamento Pessoal de Nível Superior (CAPES), Conselho Nacional de Desenvolvimento Científico e Tecnológico (MCT/ CNPq), Fundação Carlos Chagas Filho de Amparo à Pesquisa do Estado do Rio de Janeiro (FAPERJ), and Fundação Oswaldo Cruz (FIOCRUZ). The authors are grateful to Iêda Coleto Miguel de Castro and Silvia Rocha de Souza for technical support.

\section{Author details}

Alane Beatriz Vermelho ${ }^{1 *}$, Claudiu T. Supuran ${ }^{2,3}$, Verônica Cardoso ${ }^{1}$, Dayanne Menezes ${ }^{1}$, Jefferson Rocha de Andrade Silva ${ }^{4}$, Jose Luiz Pinto Ferreira ${ }^{5}$, Ana Claudia Fernandes Amaral ${ }^{5}$ and Igor A. Rodrigues ${ }^{1,6}$

*Address all correspondence to: abvermelho@micro.ufrj.br

1 Biotecnologia - Bioinovar, Instituto de Microbiologia Paulo de Góes, Universidade Federal do Rio de Janeiro, Cidade Universitária, Rio de Janeiro, Brasil

2 Istituto di Biochimica delle Proteine, CNR, Napoli, Italy

3 Università degli Studi di Firenze, NEUROFARBA Dept., Sezione di Scienze Farmaceutiche, Florence, Italy

4 Universidade Federal do Amazonas, Instituto de Ciências Exatas, Departamento de Química, Manaus-AM, Brasil

5 Laboratório de Plantas Medicinais e Derivados, Farmanguinhos, FIOCRUZ, Rio de Janeiro, Brasil

6 Faculdade de Farmácia, Departamento de Produtos Naturais e Alimentos (DPNA), Universidade Federal do Rio de Janeiro, Universitária, Rio de Janeiro, Brasil

\section{References}

[1] Centers for Disease Control and Prevention (2013). http://www.cdc.gov/parasites/ leishmaniasis/ (accessed 20 august 2013).

[2] David CV., Craft, N. Cutaneous and mucocutaneous leishmaniasis. Dermatology Therapy 2009; 22(6) 491-502. 
[3] Toledo JS., Junior PES., Manfrim V., Pinzan CF., Araújo AS., Cruz AK., Emery FS. Synthesis, Cytotoxicity and In Vitro Antileishmanial Activity of Naphthothiazoles. Chemical Biology \& Drug Design, 2013; 81(6) 749-756.

[4] Piscopo TV., Mallia AC. Leishmaniasis. Postgraduate Medical Journal 2007; 83(976) 649-657.

[5] Aguilar-Be I., Zardo RS., Souza EP., Borja-Cabrera GP., Rosado-Vallado M., MutMartin M., García-Miss MR., Sousa CBP., Dumonteil E. Cross-Protective Efficacy of a Prophylactic Leishmania donovani DNA Vaccine against Visceral and Cutaneous Murine Leishmaniasis. Infection and Immunity 2005; 73(2) 812-819.

[6] Croft SL., Sundar S., Fairlamb, AH. Drug Resistance in Leishmaniasis. Clinical Microbiology Reviews 2006; 19(1) 111- 126.

[7] World Health Organization. First WHO report on neglected tropical diseases (2010). http://whqlibdoc.who.int/publications/2010/9789241564090_eng.pdf.

[8] Cruz I., Nieto J., Moreno J., Canavate C., Desjeux P., Alvar J. Leishmania/ HIV co-infections in the second decade. Indian Journal Med. Res. 2006; 123(3) 357-388.

[9] Colomba C., Saporito L., Vitale F., Reale S., Vitale G., Casuccio A., Tolomeo M., Maranto D., Rubino R., Di Carlo P., Titone L.. Cryptic Leishmania infantum infection in Italian HIV infected patients. BMC Infectious Diseases 2009; 9(199). http:// www.biomedcentral.com/1471-2334/9/199

[10] Griensven J., Diro E., Lopez-Velez R., Boelaert M., Zijlstra LLE., Dujardin JC., Hailu A. HIV-1 protease inhibitors for treatment of visceral leishmaniasis in HIV-co-infected individuals. The Lancet Infectious Diseases 2013; 13(3), 251-259.

[11] Ehrenberg JP., Ault, SK. Neglected diseases of neglected populations: thinking to reshape the determinants of health in Latin America and the Caribbean. BMC Public Health 2005; 5 119. http://www.biomedcentral.com/1471-2458/5/119

[12] Date AA., Joshi MD., Patravale VB. Parasitic diseases: Liposomes and polymeric nanoparticles versus lipid nanoparticles. Advanced drug delivery reviews 2007; 59(6) 505-521.

[13] Croft SI., Yardley V. Chemotherapy of leishmaniasis. Current Pharmaceutical Design 2002; 8(4), 319-342.

[14] Akendengue B., Ngou-Milama E., Laurens A., Hocquemiller R. Recent Advances in the fight against leishmaniasis with natural products. Parasite 1999; 6(1) 3-8.

[15] Chatelain E., Loset JR. Drug discovery and development for neglected diseases: the DNDi model. Drug Design Development and Therapy 2011; 16(5) 175-181.

[16] Griensven J., Diro E. Visceral leishmaniasis. Infectious Disease Clinics of North America 2012; 26(2) 309-322. 
[17] Barrett M., Croft S. Management of trypanosomiasis and leishmaniasis. British Medical Bulletin 2012; 104 (1) 175-196. http://www.ncbi.nlm.nih.gov/pmc/articles/ PMC3530408/

[18] Borborema SE., Schwendener RA., Osso JA., Andrade HF., Nascimento N. Uptake and antileishmanial activity of meglumine antimoniate-containing liposomes in Leishmania (Leishmania) major-infected macrophages. International Journal of Antimicrobial Agents 2011; 38(4) 341-347.

[19] Tempone AG., Mortara RA., Andrade HF., Reimão JQ. Therapeutic evaluation of free and liposome-loaded furazolidone in experimental visceral leishmaniasis. International Journal of Antimicrobial Agents 2010; 36(2) 159-163.

[20] Jaafari, M. R.; Bavarsad, N.; Bazzaz, B. S.; Samiei, A.; Soroush, D.; Ghorbani, S.; Heravi, M. M. \& Khamesipour, A. Effect of topical liposomes containing paromomycin sulfate in the course of Leishmania major infection in susceptible BALB/c mice. Antimicrobial Agents and Chemotherapy 2009; 53(6) 2259-2265.

[21] Papagiannaros A., Bories C., Demetzos C., Loiseau PM. Antileishmanial and trypanocidal activities of new miltefosine liposomal formulations. Biomedicine \& Pharmacotherapy 2005; 59(10) 545-550.

[22] Chen M., Wang S., Tan M., Wang Y. Applications of nanoparticles in herbal medicine: zedoary turmeric oil and its active compound $\beta$-elemene. The American Journal of Chinese Medicine 2011; 39(6) 1093-1102.

[23] Edwards KA., Baeumner AJ. Liposomes in analyses. Talanta 2006; 68 (5), 1432-1441.

[24] Vemuri S., Rhodes C T. Preparation and characterization of liposomes as therapeutic delivery systems: a review. Pharmaceutica Acta Helvetica 1995; 70(2) 95-111.

[25] Batista CM., Carvalho CMB., Magalhães NSS. Lipossomas e suas aplicações terapêuticas: Estado da arte. Brazilian Journal of Pharmaceutical Sciences 2007; 43(2) 167-179.

[26] Ajazuddin SS. Applications of novel drug delivery system for herbal formulations. Fitoterapia 2010; 81(7) 680-689.

[27] Harvier P., Désormeaux A., Gagne N., Tremblay M., Poulin L., Beauchamp D. Bergeron MG. Lymphoid tissues targeting of liposome-encapsulated 2',3'-dideoxyinosine. AIDS 1995; 9(7) 701-707.

[28] Esquenazi D., Wigg MD., Miranda MMFS., Rodrigues HM., Tostes JBF., Rozental S., Silva AJR., Alviano CS. Antimicrobial and antiviral activities of polyphenolics from Cocos nucifera Linn. (Palmae) husk fiber extract. Research in Microbiology 2002; 153(10) 647-652.

[29] Kim HS. Do not put too much value on conventional medicines. Journal of Ethnopharmacology 2005; 100(1-2) 37-39. 
[30] Firenzuoli F., Gori L. Herbal medicine today: clinical and research issues. EvidenceBased Complementary and Alternative Medicine 2007; 4(1) 37-40. http:// www.ncbi.nlm.nih.gov/pmc/articles/PMC2206236/

[31] Braga FG., Bouzada ML., Fabri RL., Matos MO., Moreira FO., Scio E., Coimbra ES. Antileishmanial and antifungal activity of plants used in traditional medicine in Brazil. Journal of Ethnopharmacology 2007; 111(2) 396-402.

[32] Bero J., Hannaert V., Chataigné G., Hérent MF., Quetin-Leclercq J. In vitro antitrypanosomal and antileishmanial activity of plants used in Benin in traditional medicine and bio-guided fractionation of the most active extract. Journal of Ethnopharmacology 2011; 137(2), 998-1002.

[33] Al-Musayeib NM., Mothana RA., Matheeussen A., Cos P., Maes L. In vitro antiplasmodial, antileishmanial and antitrypanosomal activities of selected medicinal plants used in the traditional Arabian Peninsular region. BMC Complementary and Alternative Medicine, 2012; 12(49). http://www.biomedcentral.com/content/pdf/ 1472-6882-12-49.pdf

[34] González-Coloma A., Reina M., Sáenz C., Lacre, R., Ruiz-Mesia L., Arán VJ., Sanz J., Martínez-Díaz RA. Antileishmanial, antitrypanosomal, and cytotoxic screening of ethnopharmacologically selected Peruvian plants. Parasitology Research 2012; 110(4) 1381-1392.

[35] Salem MM., Werbovetz KA. Natural products from plants as drug candidates and lead compounds against leishmaniasis and trypanosomiasis. Current Medicinal Chemistry 2006; 13(21) 2571-2598.

[36] Rodrigues IA., Amaral ACF., Rosa MSS. Trypanosomatid enzymes as targets for plant-derived compounds: new perspectives for phytotherapeutic approaches. Current Enzyme Inhibition 2011; 7(1) 32-41.

[37] Wink M. Medicinal plants: A source of anti-parasitic secondary metabolites. Molecules 2012; 17(11), 12771-12791. http://www.mdpi.com/1420-3049/17/11/12771

[38] Basu MK. Liposomal Delivery of Antileishmanial Agents. Journal of Applied Research 2005; 5 (1) 221-236.

[39] Sarkar S., Mandal S., Sinha J., Mukhopadhyay S., Das N., Basu, MK. Quercetin: Critical Evaluation as an Antileishmanial Agent In Vivo in Hamsters Using Different Vesicular Delivery Modes. Journal of Drug Targeting 2002; 10(8)573-578.

[40] Van de Ven H., Vermeersch M., Matheeeussen A., Vandervoort J., Weyenberg W., Apers S., Cos P., Maes L., Ludwig A. PLGA Nanoparticles Loaded with the Antileishmanial Saponin $\beta$-Aescin: Factor Influence Study and In Vitro Efficaçy Evaluation. International Journal of Pharmaceutics 2011; 420(1) 122-132. 
[41] Sinha J., Mukhopadhyay S., Das N., Basu M.K. Targeting of Liposomal Andrographolide to L. donovani Infected Macrophages in vivo. Drug Delivery 2000; 7(4) 209-213.

[42] Lala S., Nandy AK., Mahato SB., Basu MK. Delivery in vivo of 14-deoxy-11-oxoandrographolide, an antileishmanial agent, by different drug carriers. Indian Journal of Biochemistry and Biophysics 2003; 40(3) 169-174.

[43] Garai S., Mahato SB., Ohtani K., Yamasaki K. Dammarane-Type Triterpenoid Saponins from Bacopa monniera. Phytochemistry 1996; 42(3) 815-820.

[44] Sinha J., Raay B., Das N., Medda S., Garai S., Mahato SB., Basu MK. Bacopasaponin C: critical evaluation of anti-leishmanial properties in various delivery modes. Drug Delivery 2002; 9(1) 55-62.

[45] Proulx ME., Désormeaux A., Marquis JF., Olivier M., Bergeron MG. Treatment of Visceral Leishmaniasis with Sterically Stabilized Liposomes Containing Camptothecin. Antimicrobial Agents and Chemotherapy 2001; 45(9): 2623-2627.

[46] Luz PP., Magalhães LG., Pereira AC., Cunha VR., Rodrigues V., Silva MLA. Curcumin-Loaded into PLGA Nanoparticles : preparation and in vitro schistosomicidal activity. Parasitology Research 2012; 110(2) 593-598.

[47] Basu MK., Lala S. Macrophage Specific Drug Delivery in Experimental Leishmaniasis. Current Molecular Medicine 2004; 4(6) 681-689.

[48] Lala S., Gupta S., Sahu NP., Mandal D., Mondal NB., Moulik SP., Basu MK. Critical Evaluation of the Therapeutic Potential of Bassic Acid Incorporated in Oil-in-Water Microemulsions and Poly-D,L-Lactide Nanoparticles Against Experimental Leishmaniasis. Journal of Drug Targeting 2006; 14(4) 171-179.

[49] Mukhopadhyay S., Banerjee SK., Atal CK., Lin LJ., Cordell, GA. Alkaloids of Corydalis govaniana. Journal of Natural Products 1987; 50(2) 270-273.

[50] Lala S., Pramanick S., Mukhopadhyay S., Bandyopadhyay S., Basu M.K. Harmine Evaluation of its Antileishmanial Properties Invarious Vesicular Delivery Systems. Journal of Drug Targeting 2004; 12(3) 165-175.

[51] Torres-Santos EC., Rodrigues JM., Moreira DL., Kaplan MAC., Rossi-Bergmann B. Improvement of In Vitro and In Vivo Antileishmanial Activities of 2',6'-Dihydroxy-4'-Methoxychalcone by Entrapment in Poly(D,L-Lactide) Nanoparticles. Antimicrobial Agents and Chemotherapy 1999; 43(7) 1776-1778.

[52] Raay B., Medda S., Mukhopadhyay S., Basu MK. Targeting of piperine intercalated in mannose-coated liposomes in experimental leishmaniasis. Indian Journal of Biochemistry and Biophysics 1999; 36(4) 248-251. 
[53] Veerareddy PR., Vobalaboina V., Nahid, A. Formulation and Evaluation of Oil-inWater Emulsions of Piperine in Visceral Leishmaniasis. Pharmazie 2004; 59(3) 194-197.

[54] Ray S., Majumder K., Chakravarty AK., Mukhopadhyay S., Gil RR., Cordell GA. Amarogentin, a Naturally Occurring Secoiridoid Glycoside and a Newly Recognized Inhibitor of Topoisomerase I from Leishmania donovani. Journal of Natural Products 1996; 59(1) 27-29.

[55] Medda S., Mukhopadhyay S., Basu MK. Evaluation of the In Vivo Activity and Toxicity of Amarogentin, an Antileishmanial Agent, in Both Liposomal and Niosomal Forms. Journal of Antimicrobial Chemotherapy 1999; 44(6) 791-794.

[56] Georgopoulou K., Smirlis D., Bisti S., Xingi E., Skaltsounis L., Soteriadou K. In Vitro Activity of 10-Deacetylbaccatin III Against Leishmania donovani Promastigotes and Intracellular Amastigotes. Planta Medica 2007; 73(10) 1081-1088.

[57] Tyagi R., Lala S., Verma AK., Nandy AK., Mahato SB., Maitra A., Basu MK. Targeted Delivery of Arjunglucoside I Using Surface Hydrophilic and Hydrophobic Nanocarriers to Combat Experimental Leishmaniasis. Journal of Drug Targeting 2005; 13(3) 161-171.

[58] Ferreira M.E., Arias ASR., Ortiz ST., Inchausti A., Nakayama H., Thouvenel C., Hocquemiller R., Fournet A. Leishmanicidal Activity of Two Canthin-6-one Alkaloids, Two Major Constituents of Zanthoxylum chiloperone var. angustifolium. Journal of Ethnopharmacology 2002; 80(2-3), 199-202.

[59] Arias JL, Cebrián-Torrejón G., Poupon E., Fournet A. Couvreur P. Biodegradable Polymeric Nanoformulation Based on the Antiprotozoal Canthin-6-one. Journal of Nanoparticle Research 2011; 13(12) 6737-6746. http://link.springer.com/article/ 10.1007\%2Fs11051-011-0580-z\#page-1

[60] Hadaruga DI., Hadãruga NG., Bandur GN., Rivis A., Costescu C., Ordodi VL., Ardelean A. Berberis vulgaris extract $/ \beta$-cyclodextrin nanoparticles synthesis and characterization. Revista de Chimie (Bucharest) 2010; 61(7) 669-675.

[61] Sanna V., Siddiqui IA., Sechi M., Mukhtar H. Nanoformulation of natural products for prevention and therapy of prostate cancer. Cancer Letters 2013; 334(1) 142-151.

[62] Silva AM., Tavares J., Silvestre R., Ouaissi A., Coombs GH., Silva AC. Characterization of Leishmania infantum thiol-dependent reductase 1 and evaluation of its potential to induce immune protection. Parasite Immunology 2012; 34(6) 345-50.

[63] Manjolin LC., Reis MB., Maquiaveli, CC., Santos-Filho OA., Silva, ER. Dietary flavonoids fisetin, luteolin and their derived compounds inhibit arginase, a central enzyme in Leishmania (Leishmania) amazonensis infection. Food Chemistry 2013; 141(3) 2253-2262.

[64] Fonseca-Silva, F., Inacio JD., Canto-Cavalheiro MM., Almeida-Amaral EE. Reactive oxygen species production and mitochondrial dysfunction contribute to quercetin in- 
duced death in Leishmania amazonensis. PLoS One 2011; 6, (2) 14666. http:// www.plosone.org/article/info:doi/10.1371/journal.pone.0014666

[65] Fonseca-Silva F., Inacio JD., Canto-Cavalheiro MM., Almeida-Amaral EE. Reactive oxygen species production by quercetin causes the death of Leishmania amazonensis intracellular amastigotes. Journal of Natural Products 2013; 76(8) 1505-1508. http:// pubs.acs.org/doi/abs/10.1021/np400193m

[66] Roy P., Das S., Bera T., Mondol S., Mukherjee A. Andrographolide nanoparticles in leishmaniasis: characterization and in vitro evaluations. International Journal of Nanomedicine 2010; 5(1) 1113-1121. http://www.ncbi.nlm.nih.gov/pmc/articles/ PMC3023240/

[67] Lala S., Nandy AK., Mahato SB., Basu MK. Delivery In Vivo of 14-Deoxy-11-Oxoandrographolide, an Antileishmanial Agent, by Different Drug Carriers. Indian journal of Biochemistry \& Biophysics 2003; 40(3) 169-174.

[68] Vasir JK., Reddy MK., Labhasetwar VD. Nanosystems in drug targeting: opportunities and challenges. Current Nanoscience 2005; 1(1) 47-64.

[69] Das S., Roy P., Mondal S., Bera T., Mukherjee, A. One Pot Synthesis of Gold Nanoparticles and Application in Chemotherapy of Wild and Resistant Type Visceral Leishmaniasis. Colloids and Surfaces B: Biointerfaces 2013; 107(1) 27-34.

[70] Kapil A. Piperine: a potent inhibitor of Leishmania donovani promastigotes in vitro. Planta Medica 1993; 59(5) 474.

[71] Ferreira C., Soares DC., Barreto-Junior CB., Nascimento MT., Lima LF., Delorenzi JC., Lima M E., Atella GC., Folly E., Carvalho TM., Saraiva EM., Silva LHP. Leishmanicidal effects of piperine, its derivatives, and analogues on Leishmania amazonensis. Phytochemistry 2011; 72(17) 2155-2164.

[72] Di Giorgio C., Delmas F., Ollivier E., Elias R., Balansard G., Timon-David P. In vitro activity of the beta-carboline alkaloids harmane, harmine, and harmaline toward parasites of the species Leishmania infantum. Experimental Parasitology 2004; 106(3-4), 67-74.

[73] Gil ES., Cunha LC., Paula, J. R., Bezerra JCB., Aguiar FA. Leishmaníase: Arsenal Terapêutico e Alvos Moleculares. Vita et Sanitas 2007; 1(1). http://www.fug.edu.br/revista/artigos/Organizados/Leishmaniase.pdf.

[74] Melos JLR., Echevarria A. Sistemas Enzimáticos de Tripanossomatídeos como Potenciais Alvos. Quimioterápicos. Revista Virtual de Quimíca 2012; 4(4) 374-392.

[75] Genestra M., Guedes SD., Souza WJS., Cysne-Finkelstein L., Bezerra RJS., Monteiro FP., Leon LL. Nitric Oxide Synthase (NOS) Characterization in Leishmania amazonensis Axenic Amastigotes, Archives of Medical Research 2006; 37(3) 328-333. 
[76] Dias LC., Dessoy MA., Silva JJN., Thiemann OH., Oliva G., Andricopulo AD. Chemotherapy of chagas' disease: state of the art and perspectives for the development of new drugs. Quimica Nova 2009; 32(9) 2444-2457.

[77] Reguera MR., Tekwani BL., Balaña-Fouce R. Poliamine transport in parasites: A potential target for new antiparasistic drug development. Comparative Biochemistry and Physiology. Part C, 2005; 140(2) 151-164. http://europepmc.org/abstract/MED/ 15907761/reload=0;jsessionid=rJHFy2UYQHdnHPOLt0dI.50

[78] Roberts SC. Genetic manipulation of Leishmania parasites facilitates the exploration of the polyamine biosynthetic pathway as a potential therapeutic target. In: Urbano KV. (ed.) Advances in Genetics Research Hauppauge, NY: Nova Science Publishers; 2013. p 29-54.

[79] Padmanabhan PK., Mukherjee A., Singh S., Chattopadhyaya S., Gowri VS., Myler PJ., Srinivasan N., Madhubala R. Glyoxalase I from Leishmania donovani: A potential target for anti-parasite drug. Biochemical and Biophysical Research Communications 2005 ; 337(4) 1237-1248.

[80] Sousa SM., Gomes RA., Ferreira AE, Ponces FA., Cordeiro C. The glyoxalase pathway: the first hundred years... and beyond. The Biochemical Journal 2013; 453(1) 115.

[81] Lepesheva GI., Hargrove TY., Anderson S., Kleshchenko Y., Furtak V., Wawrzak Z., Villalta F., Waterman M. Sterol $14 \alpha$-demethylase as a potential target for antitrypanosomal therapy: enzyme inhibition and parasite cell growth. Chemistry and Biology 2007; 14(11) 1283-1293.

[82] Zhang K., Beverle SM. Molecular \& Biochemical Parasitology Phospholipid and sphingolipid metabolism in Leishmania Review Article Molecular and Biochemical Parasitology 2010; 170(2) 55-64.

[83] Libusová L., Sulimenko T., Sulimenko V., Hozák P., Dráber P. Gamma- Tubulin in Leishmania: cell cycle-dependent changes in subcellular localization and heterogeneity of its isoforms, Experimental Cell Research 2004; 295(2) 375-386.

[84] Najwa MJA., Abu-Mejdad, Al-Hilfy AAA. Evaluation of therapeutic effects of vicine against Leishmania donovani. in vitro. The Journal American Science 2013; 9(5) 115-120. http://www.jofamericanscience.org/journals/am-sci/ am0905/016_17646am0905_115_120.pdf

[85] Gangjee A., Jain HD., Kurup S. Recent advances in classical and non-classical antifolates as antitumor and antiopportunistic infection agents: part I. Anticancer Agents in Medicinal Chemistry 2007; 7(5) 524-42.

[86] Takele Y., Abebe T., Weldegebreal T., Hailu A., Hailu W., Hurissa Z., Ali J., Diro E., Sisay, Y., Cloke T., Modolell M., Munder M., Tacchini-Cottier F., Müller, I., Kropf P. 
Arginase activity in the blood of patients with visceral leishmaniasis and HIV infection. PLoS Neglected Tropical Diseases 2013; 7 (1) 1-7.

[87] Luz NF., Andrade BB., Feijó, DF., Araújo-Santos T., Carvalho GQ., Andrade D., Abánades DR., Melo EV., Silva AM., Brodskyn CI., Barral-Netto M., Barral A., Mahmoudzadeh-Niknam H., McKerrow JH. Leishmania tropica: cysteine proteases are essential for growth and pathogenicity. Experimental Parasitology 2004; 106(3-4) 158-163.

[88] Kaur PK., Dinesh N., Soumya N., Babu NK.; Singh S. Identification and characterization of a novel Ribose 5-phosphate isomerase B from Leishmania donovani. Biochemical and Biophysical Research Communications 2012; 421(1) 51-56.

[89] Cordeiro AT., Feliciano, P. R.; Pinheiro, M. P.; Nonato, M. C. (2012). Crystal structure of dihydroorotate dehydrogenase from Leishmania major. Biochimie. 8(94) 1739-1748.

[90] Rotella DP. Recent results in protein kinase inhibition for tropical diseases. Bioorganic and Medicinal Chemistry Letters 2012; 22(22) 6788-6793.

[91] Wetze DMl, McMahon-Pratt D., Koleske AJ. The Abl and Arg Kinases Mediate Distinct Modes of Phagocytosis and Are Required for Maximal Leishmania Infection Molecular and Cellular Biolology 2012; 32(15) 3176-3186.

[92] Cummings HE., Barbi J., Reville P., Oghumu S., Zorko N., Sarkar A., Keiser TL., Lu B., Rückle T., Varikuti S., Lezama-Davila C., Wewers MD., Whitacre, C.; Radzioch, D.; Rommel C., Seveau S., Satoskar AR. Critical role for phosphoinositide 3-kinase gamma in parasite invasion and disease progression of cutaneous leishmaniasis. Proceedings of the National Academy Sciences 2012; 109(4) 1251-1256.

[93] Singh N., Kumar M., Singh RK. Leishmaniasis: current status of available drugs and new potential drug targets. Asian Pacific Journal of Tropical Medicine 2012; 5(6) 485-97.

[94] Gilroy C., Olenyik T., Roberts SC., Ullman B. Spermidine synthase is required for virulence of Leishmania donovani. Infection and Immunity 2011; 79(7) 2764-2769. http:// www.ncbi.nlm.nih.gov/pubmed/21536795

[95] Grover A., Katiyar SP., Singh, SK., Dubey VK., Sundar D. A leishmaniasis study: structure-based screening and molecular dynamics mechanistic analysis for discovering potent inhibitors of spermidine synthase. Biochimica et Biophysica Acta - Proteins and Proteomics 2012; 1824(12) 1476-1483. http://www.sciencedirect.com/ science/article/pii/S1570963912001136

[96] Mahmoudzadeh-Niknam H., McKerrow J.H. Leishmania tropica: cysteine proteases are essential for growth and pathogenicity. Experimental Parasitology 2004; 106(3-4) 158-163.

[97] Lopez RES. Proteases de Leishmania: novos alvos para o desenvolvimento racional de fármacos. Química Nova 2010; 33(7) 1541-1548. 
[98] Swenerton RK., Zhang S., Sajid M., Medzihradszky KF., Craik CS., Kelly BL., McKerrow $\mathrm{JH}$. The oligopeptidase $\mathrm{B}$ of Leishmania regulates parasite enolase and immune evasion. The Journal Biology Chemistry 2011; 286(1) 429-40.

[99] Jäger W., Santag S., Weidner-Glunde M., Gellermann E., Kati S., Pietrek M., ViejoBorbolla A., Schulz TF. The ubiquitin-specific protease USP7 modulates the replication of Kaposi's sarcoma-associated herpesvirus latent episomal DNA. Journal of Virology 2012; 86(12) 6745-6757.

[100] Supuran CT. Carbonic anhydrase inhibition/activation: trip of a scientist around the world in the search of novel chemotypes and drug targets. Current Pharmaceutical Design 2010; 16(29) 3233-3245.

[101] Neri D., Supuran CT. Interfering with $\mathrm{pH}$ regulation in tumours as a therapeutic strategy. Nature Reviwens Drug Discovery 2011; 10(10) 767-777. http:// www.nature.com/nrd/journal/v10/n10/abs/nrd3554.html

[102] Syrjänen L, Vermelho AB, de Rodrigues IA., Corte-Real S, Salonen T, Pan P, Vullo D, Parkkila S, Capasso C, Supuran CT. Cloning, Characterization, and Inhibition Studies of a $\beta$-Carbonic Anhydrase from Leishmania donovani chagasi, the Protozoan Parasite Responsible for Leishmaniasis. Journal of Medicinal Chemistry 2013; 56(18) 7372-7381.

[103] Urbina JA. Specific chemotherapy of Chagas disease: relevance, current limitations and new approaches. Acta Tropica 2010; 115(1-2) 55-68.

[104] Schetelma RA., Decuypere S., T'Kindt R., Dujardin JC., Coombs GR., Breitling G. The potential of metabolomics for Leishmania research in the post-genomics era. Parasitology 2010; 137(9) 1291-1302.

[105] Ogungbe VI., Setzer WN. In-silico Leishmania Target Selectivity of Antiparasitic Terpenoids Molecules 2013; 18(7) 7761-7847.

[106] Antinori S., Schifanella L., Corbellino M. Leishmaniasis: new insights from an old and neglected disease. European Journal of Clinical Microbiology and Infectious Diseases 2011; 31(2) 109-118.

[107] Alvar J., Croft S., Olliaro P. Chemotherapy in the treatment and control of leishmaniasis. Advances in Parasitology 2006; 61(1) 223-274. http://www.sciencedirect.com/ science/article/pii/S0065308X05610068

[108] Cardenas R., Sandoval CM., Rodriguez-Morales AJ., Franco-Paredes C. Impact of climate variability in the occurrence of leishmaniasis in northeastern Colombia. The American Journal Tropical of Medicinal and Hygiene 2006; 75(2) 273-277.

[109] Field V., Gautret P., Schlagenhauf P., Burchard GD., Caumes E., Jensenius M., Castelli F., Gkrania-Klotsas E., Weld L., Lopez-Velez R., Vries P., Von Sonnenburg F., Loutan L., Parola P. Travel and migration associated infectious diseases morbidity in 
Europe, 2008. BMC Infections Diseases 2010; 10(330). http://www.biomedcentral.com/1471-2334/10/330 (accessed 15 August 2013).

[110] Volpato H., Desoti VC., Cogo J., Panice MR., Sarragiotto MH., Silva SO., Ueda-Nakamura T., Nakamura CV. The Effects of N-Butyl-1-(4-dimethylamino)phenyl-1,2,3,4tetrahydro- $\beta$-carboline-3-carboxamide against Leishmania amazonensis Are Mediated by Mitochondrial Dysfunction. Evidence-Based Complementary and Alternative Medicine 2013; 2013 (874367) 1-7. http://www.hindawi.com/journals/ecam/ 2013/874367/ (accessed 10 August 2013).

[111] Tolomeo M., Roberti M., Scapozza L., Tarantelli C., Giacomini E.; Titone L., Saporito L., Di Carlo P., Colomba C. TTAS a new stilbene derivative that induces apoptosis in Leishmania infantum. Experimental Parasitology 2013; 3(1) 37-43.

[112] Gohil VM., Brahmbhatt KG., Loiseau PM., Bhutani KK. Synthesis and anti-leishmanial activity of 1-aryl-b-carboline derivatives against Leishmania donovani. Bioorganic and Medicinal Chemistry Letters 2012; 22(12) 3905-3907.

[113] Bahar M., Deng Y., Zhu X., He S., Pandharkar T., Drew ME., Navarro-Vázquez A., Anklin C., Gil RR., Doskotch RW., Werbovetz KA., Kinghorn A.D. Potent antiprotozoal activity of a novel semi-synthetic berberine derivative. Bioorganic and Medicinal Chemistry Letters 2011; 21(9) 2606-2610.

[114] Miguel CD., Yokoyama-Yasunaka JKU., Uliana SRB. Tamoxifen Is Effective in the Treatment of Leishmania amazonensis Infections in Mice PLoS Neglected Tropical Diseases 2008; 2(6)249. http://www.ncbi.nlm.nih.gov/pmc/articles/PMC2398787/

[115] Hazra SJ., Ghosh S., Das SM., Sharma S., Mousumi Das, Saudagar P., Prajapati, VK., Dubey VK., Sundar S., Hazra B. Evaluation of a diospyrin derivative as antileishmanial agent and potential modulator of ornithine decarboxylase of Leishmania donovani. Experimental Parasitology 2013; 135(2) 407-413. http://www.sciencedirect.com/ science/article/pii/S0014489413002075

[116] Balaña-Fouce R., Prada CF., Requena JM., Cushman M., Pommier Y., Álvarez-Velilla R., Escudero-Martínez JM., Calvo-Álvarez E., Pérez-Pertejo Y., Reguera RM. Indotecan (LMP400) and AM13-55: Two Novel Indenoisoquinolines Show Potential for Treating Visceral Leishmaniasis. Antimicrobial Agents and Chemotherapy 2012; 56(10) 5264-5270.

[117] Allahverdiyev AM., Abamor ES., Bagirova M., Baydar SY., Ates SC., Kaya F., Kaya C., Rafailovich M. Investigation of antileishmanial activities of Tio2@Ag nanoparticles on biological properties of L. tropica and L. infantum parasites, in vitro. Experimental Parasitology 2013; 135(1) 55-63.

[118] Abada Z, Cojean S, Pomel S, Ferrié L, Akagah B, Lormier AT, Loiseau PM, Figadère B. Synthesis and antiprotozoal activity of original porphyrin precursors and derivatives. European Journal of Medicinal Chemistry 2013; 67(12) 158-165. 
[119] Shakya N., Sane SA., Vishwakarma P., Gupta S. Enhancement in therapeutic efficacy of miltefosine in combination with synthetic bacterial lipopeptide, Pam3Cys against experimental Visceral Leishmaniasis. Experimental Parasitology 2012; 131(3) 377-82. 